\title{
Endovascular management of a vein of Galen aneurysmal malformation in an infant with challenging femoral arterial access
}

\author{
Bharathi D. Jagadeesan, MD, ${ }^{1-3}$ Haralabos Zacharatos, DO, ${ }^{3}$ David R. Nascene, MD, ${ }^{1}$ \\ Andrew W. Grande, MD, ${ }^{1-3}$ Daniel J. Guillaume, MD, ${ }^{2}$ and Ramachandra P. Tummala, MD ${ }^{1-3}$ \\ Departments of ${ }^{1}$ Radiology, ${ }^{2}$ Neurosurgery, and ${ }^{3}$ Neurology, University of Minnesota, Minneapolis, Minnesota
}

\begin{abstract}
A 5-month-old infant was to be treated with elective transarterial embolization for a vein of Galen aneurysmal malformation (VGAM). A team of endovascular surgical neuroradiologists, pediatric interventional radiologists, and pediatric cardiologists attempted conventional femoral arterial access, which was unsuccessful given the small caliber of the femoral arteries and superimposed severe vasospasm. Thereafter, eventual arterial access was achieved by navigating from the venous to the arterial system across the patent foramen ovale following a right femoral venous access. Embolization was then successfully performed. At a later date, the child underwent successful transvenous balloon-assisted embolization and eventual arterial embolization with cure of the VGAM.
\end{abstract}

http://thejns.org/doi/abs/10.3171/2016.2.PEDS15652

KEY WORDS vein of Galen malformation; patent foramen ovale; transvenous embolization; vascular disorders

$\mathrm{V}$ EIN of Galen aneurysmal malformations (VGAMs) are complex congenital malformations that can be managed with endovascular embolization in selected clinical settings. Transarterial endovascular embolization remains the cornerstone of treatment in patients with these malformations; however, arterial access can be challenging in newborns and infants. This can be especially true in the setting of staged embolization procedures.

\section{Case Report}

History and Examination

A male infant was diagnosed with a mixed mural and choroidal type of VGAM (Fig. 1) and right atrial enlargement at birth. The child did not have congestive cardiac failure, seizures, or hydrocephalus. He also had partial anomalous pulmonary venous return (PAPVR), sinus venous type of atrial septal defect, and bidirectional flow across a patent foramen ovale (PFO) with right atrial enlargement.

\section{First Treatment}

Elective transarterial embolization was scheduled when the child was 5 months old to allow for eventual openheart surgery and correction of the PAPVR, which was originally planned for between 10 and 12 months of age (but eventually deferred until the age of 18-24 months given the reduction in preload to the heart following treatment of the VGAM). Timing of the elective embolization procedure was chosen in light of prior reports by other authors. ${ }^{1,7}$ Transvenous embolization was not favored because of its known poorer outcomes, the pial venous reflux,,$^{1,7}$ as well as the risk of paradoxical embolization and stroke in the presence of a PFO with bidirectional shunting.

Multiple attempts to obtain arterial access through either of the common femoral arteries proved unsuccessful despite the assistance of pediatric interventional radiology and pediatric cardiology teams as well as the use of ultrasonographic guidance. The arteries were very small caliber and very prone to vasospasm. Access through the brachial arteries was considered, but the small caliber of

ABBREVIATIONS DS = digital subtraction; PAPVR = partial anomalous pulmonary venous return; PFO = patent foramen ovale; VGAM = vein of Galen malformation . SUBMITTED November 6, 2015. ACCEPTED February 10, 2016.

INCLUDE WHEN CITING Published online April 8, 2016; DOI: 10.3171/2016.2.PEDS15652. 

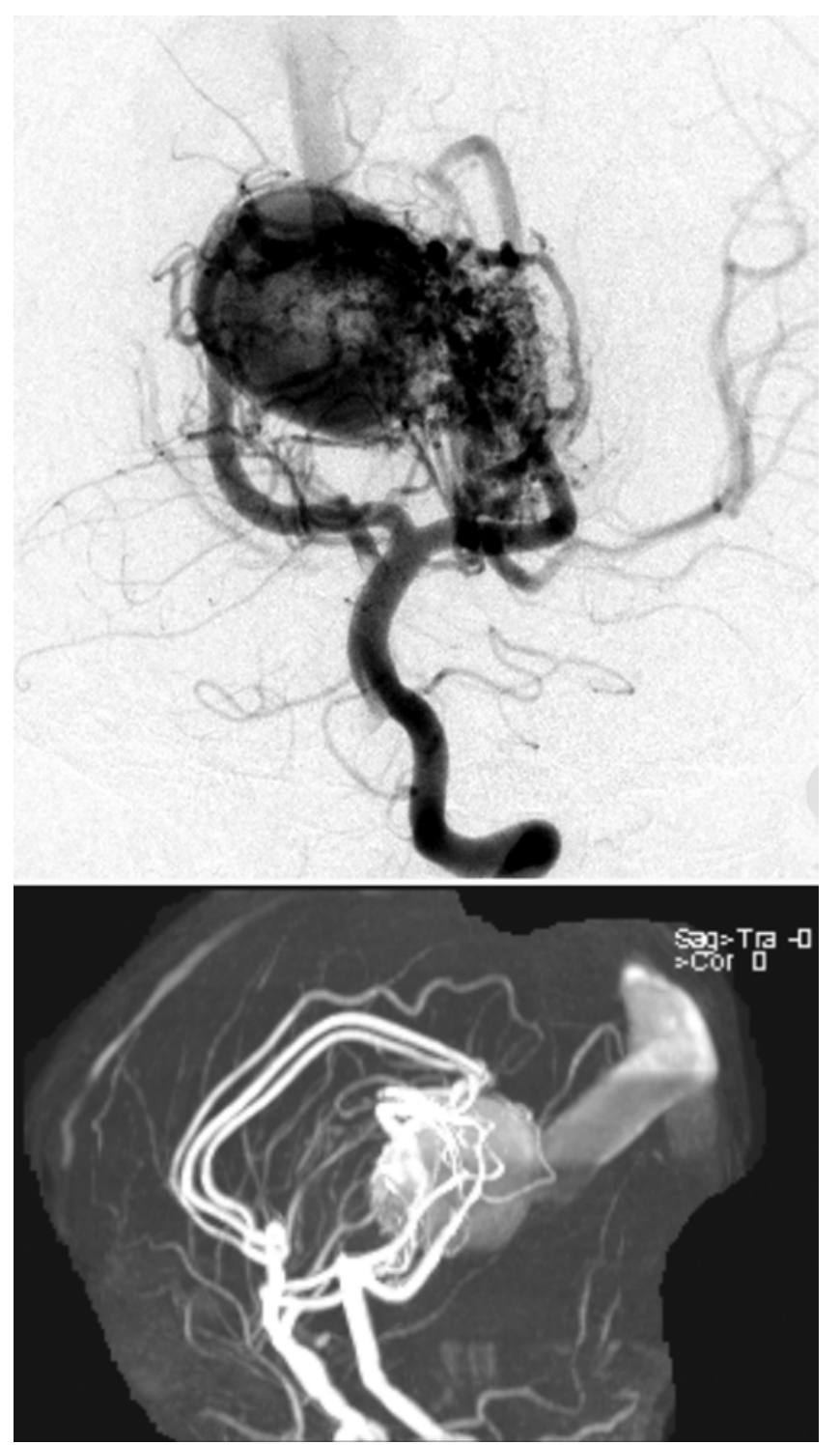

FIG. 1. Frontal digital subtraction (DS) angiogram (upper) obtained following left vertebral artery injection in the 5-month-old patient, showing a VGAM with posterior choroidal, thalamo-perforator, and subependymal feeders and rapid arteriovenous shunting. Maximum intensity projection reconstruction of a time-of-flight MR angiogram (lower), lateral view, obtained a few days earlier, demonstrating the VGAM.

these arteries precluded the placement of a 4-Fr vascular sheath.

Eventually, a 5-Fr vascular sheath was placed in the right common femoral vein, and a 4-Fr balloon catheter was advanced into the right atrium over a glide wire. The glide wire was exchanged for a Bentson wire, the balloon was inflated, the system was advanced until the PFO was engaged, and then it was further advanced into the left atrium and eventually the left ventricle. The balloon catheter was used to minimize the chances of perforation of the cardiac structures. The balloon catheter was then deflated and exchanged for a 5-Fr angled glide catheter (Terumo Corp.), which was advanced into the ascending aorta, and the left internal carotid artery was selected (Fig. 2). Transarterial embolization was then performed via the


FIG. 2. Frontal digital spot images showing a 5-Fr glide catheter passed from the venous to the arterial side across the PFO in the 5-month-old patient. Notice the variation in the diameter of the loop formed by the catheter within the heart from diastole (left) to systole (right). Also note the tip of the catheter within the left common carotid artery.

injection of ethylene vinyl alcohol copolymer (Onyx) into the arterial feeders to the VGAM from the distal left pericallosal artery. Approximately $30 \%$ of the feeding arteries to the VGAM were embolized at this stage, and the child was discharged home without complications.

\section{Second Treatment}

The child underwent repeat MR angiography at 1 year of age, which showed an interval increase in flow through the VGAM and the recruitment of more arterial feeders. Femoral arterial access continued to be challenging given the small caliber of the vessels. At this time we determined that transvenous embolization might be safe as long as we could prevent the excessive reflux of Onyx into the venous system and premature thrombosis of the entire VGAM pouch prior to the elimination of all arterial feeders.

The largest venous channel, which drained the choroidal nidus into the inferior and anterior wall of the venous pouch, was catheterized with a $4 \times 11-\mathrm{mm}$ Scepter XC balloon microcatheter (MicroVention Inc.) using a 6-Fr guide catheter advanced from a femoral venous puncture for support. The tip of the balloon microcatheter was advanced as close to the nidus as possible (Fig. 3). The balloon was inflated, and a few detachable coils were first placed in the vein through the balloon microcatheter to reduce the flow of blood into the pouch. Onyx 18 was then injected under balloon inflation, resulting in good retrograde penetration of the nidus and feeding arteries without reflux into the VGAM pouch.

\section{Third Treatment}

Six months later a third and final curative embolization was performed via a conventional transarterial route, with the elimination of arteriovenous shunting (Fig. 4). After the final embolization, the child developed a dysconjugate gaze and needed corrective lenses and occupational therapy but has otherwise remained neurologically intact.

\section{Discussion}

The endovascular management of neonatal and infant cerebrovascular malformations requires adapting the catheters and other devices designed for adults for use in children, who have much smaller blood vessels. In the patient 

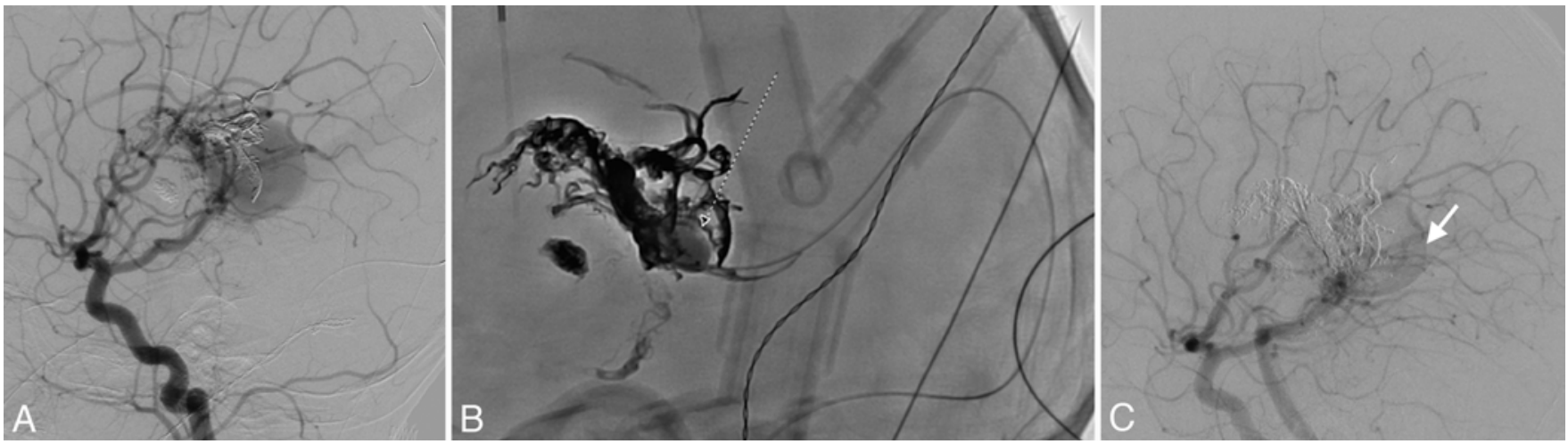

FIG. 3. Digital subtraction angiogram (A), lateral projection, obtained in the patient at 1 year of age after injection of the left common carotid artery, showing arterial flow from the choroidal arteries into a large midline VGAM. Digital spot image (B), lateral projection, showing an inflated Scepter XC balloon microcatheter (dotted arrow), which was navigated into a large draining vein that drains into the anterior and inferior wall of the VGAM. Post-transvenous embolization DS angiogram (C), lateral projection, obtained after injection of the left common carotid artery, showing a significant reduction in arterial flow into the malformation, although the venous pouch (arrow) can still be seen to faintly opacify.

in this report, we were unable to obtain adequate arterial access for VGAM treatment despite diligent efforts by multiple specialists. However, we were able to gain arterial access via the PFO. The PFO is an opening in the interatrial septum that enables fetal blood to flow from the right atrium to the left atrium. Although the PFO should close spontaneously in postnatal life by apposition of a valve to the fossa ovalis, this does not always happen and PFOs can be found in up to $21 \%$ of adults. ${ }^{2,5}$ To avoid ventricular ectopy, cautious navigation was required in using the PFO to gain arterial access, and the pediatric cardiology team was readily available to help. Likewise, a balloon catheter was used to cross the PFO and the mitral valve to minimize chances of injury to the cardiac structures, a standard practice in pediatric cardiology laboratories for a right to left approach. This technique should therefore be used only in a multispecialty setting.

The use of balloon-assisted Onyx embolization, in- cluding in children with VGAMs, has been well described elsewhere. ${ }^{69}$ Likewise, non-balloon-assisted retrograde embolization techniques have been recently described. 3,8 We think that a balloon-assisted retrograde embolization technique can add to the safety margin of this approach by preventing excessive and premature reflux of Onyx into the venous system. This may be especially true when the transvenous technique is used to deal with very high flow malformations. Balloon assistance may also lead to better penetration of Onyx, as suggested by a recent animal study. ${ }^{4}$

\section{Conclusions}

In rare instances of very young children with a VGAM or similar cerebrovascular malformation with poor femoral arterial access, it might be possible to access the arterial system via a transcardiac approach or a retrograde transvenous approach as described here.
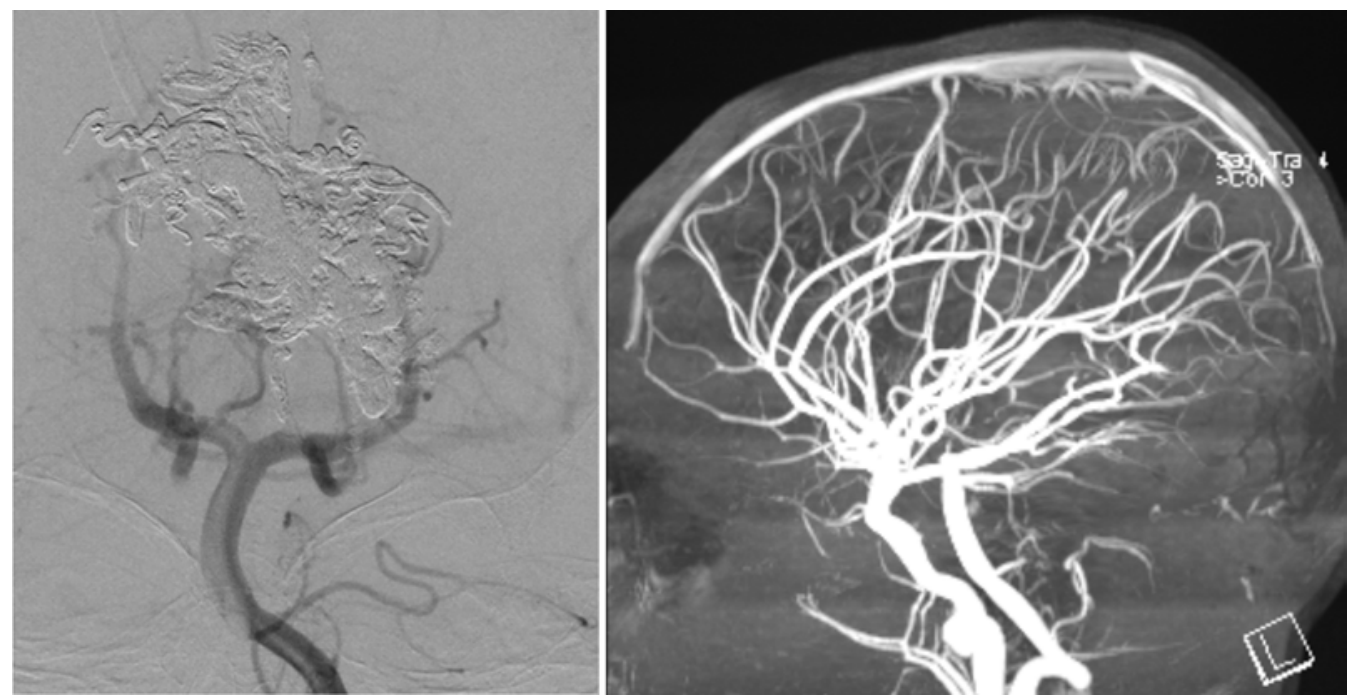

FIG. 4. Post-curative embolization frontal DS angiogram (left) obtained after left vertebral artery injection, showing the elimination of arteriovenous shunting. Maximum intensity projection reconstruction of a time-of-flight MR angiogram, lateral view, obtained in the patient a few days later, showing nothing indicative of arteriovenous shunting (right). 


\section{References}

1. Berenstein A, Ortiz R, Niimi Y, Elijovich L, Fifi J, Madrid $\mathrm{M}$, et al: Endovascular management of arteriovenous malformations and other intracranial arteriovenous shunts in neonates, infants, and children. Childs Nerv Syst 26:1345-1358, 2010

2. Calvert PA, Rana BS, Kydd AC, Shapiro LM: Patent foramen ovale: anatomy, outcomes, and closure. Nat Rev Cardiol 8:148-160, 2011

3. Cooke D, Tatum J, Farid H, Dowd C, Higashida R, Halbach $\mathrm{V}$ : Transvenous embolization of a pediatric pial arteriovenous fistula. J Neurointerv Surg 4:e14, 2012

4. Gentric JC, Raymond J, Batista A, Salazkin I, Gevry G, Darsaut TE: Dual-lumen balloon catheters may improve liquid embolization of vascular malformations: an experimental study in Swine. AJNR Am J Neuroradiol 36:977-981, 2015

5. Hagen PT, Scholz DG, Edwards WD: Incidence and size of patent foramen ovale during the first 10 decades of life: an autopsy study of 965 normal hearts. Mayo Clin Proc 59:1720,1984

6. Jagadeesan BD, Grigoryan M, Hassan AE, Grande AW, Tummala RP: Endovascular balloon-assisted embolization of intracranial and cervical arteriovenous malformations using dual lumen co-axial balloon microcatheters and Onyx: initial experience. Neurosurgery [epub ahead of print], 2013

7. Lasjaunias PL, Chng SM, Sachet M, Alvarez H, Rodesch G, Garcia-Monaco R: The management of vein of Galen aneurysmal malformations. Neurosurgery 59 (5 Suppl 3):S184S194, S3-S13, 2006
8. Pereira VM, Marcos-Gonzalez A, Radovanovic I, Bijlenga P, Narata AP, Moret J, et al: Transvenous embolization of a ruptured deep cerebral arteriovenous malformation. A technical note. Interv Neuroradiol 19:27-34, 2013

9. Pop R, Manisor M, Wolff V, Kehrli P, Marescaux C, Beaujeux R: Flow control using Scepter ${ }^{\mathrm{TM}}$ balloons for Onyx embolization of a vein of Galen aneurysmal malformation. Childs Nerv Syst 31:135-140, 2015

\section{Disclosures}

Dr. Guillaume is a consultant for Shire.

\section{Author Contributions}

Conception and design: Jagadeesan, Nascene. Acquisition of data: Jagadeesan, Zacharatos, Nascene, Guillaume. Analysis and interpretation of data: Jagadeesan, Zacharatos. Drafting the article: Jagadeesan, Zacharatos. Critically revising the article: Jagadeesan, Nascene, Grande, Tummala. Reviewed submitted version of manuscript: Jagadeesan, Grande. Approved the final version of the manuscript on behalf of all authors: Jagadeesan. Study supervision: Jagadeesan, Tummala.

\section{Correspondence}

Bharathi D. Jagadeesan, Department of Radiology and Neurosurgery, University of Minnesota, MMC 292, 420 Delaware St. SE, Minneapolis, MN 55455. email: jagad002@umn.edu. 